\section{Improvement of Quantita- tive PCR Reproducibility by Betaine as Determined by Fluorescence-Based Method}

\section{BioTechniques 30:950-954 (May 2001)}

Quantitative PCR assays incorporating an internal standard with the target cDNA may result in the formation of unexpected fragments due to in vitro recombination during $\mathrm{PCR}(5,16)$ or to heteroduplex formation when the DNA fragments are analyzed by agarose gel electrophoresis (1). The mechanisms responsible for recombinant molecule formation during PCR are incomplete chain synthesis and template switching $(9-11,13)$. In vitro recombination between two templates may occur during PCR if they share 7-9 bases of homology (2). The use of additives (8) or modifying the nucleotides (2) may affect recombination by influencing the association of the enzyme to the template (3) or the binding of DNA strands to each other $(9,11,12)$ during PCR.

We previously found that in vitro recombination between a sequence of the break point cluster region (BCR) gene on chromosome 22 and a homologous internal standard may be reduced or suppressed by increasing extension time, reducing the number of amplification cycles, or incorporating additives such as formamide, glycerol, dimethyl sulfoxide (DMSO), or betaine in the PCR (13). We found $1 \mathrm{M}$ betaine or $10 \%$ DMSO to be the most efficient additives in inhibiting recombination. We therefore wanted to test out the effect in vitro recombination had on the results of quantitative PCR when the products were analyzed under denaturing conditions and whether additives improved the reproducibility of the assay.

In this study, we quantitatively measured the amount of recombinant molecules formed during PCR when BCR cDNA was co-amplified with a homologous internal standard using Taq DNA polymerase. RNA isolation, cDNA synthesis, the construction of the homologous BCR internal standard, and the PCR conditions have been previ- ously described $(13,14)$. The products were analyzed under denaturing conditions using capillary electrophoresis followed by detection of the fluorescently labeled products. The homologous BCR internal standard was constructed to be asymmetrically shorter at both the $5^{\prime}$ end and the $3^{\prime}$ end compared to the target BCR cDNA. Thus, the two additional fragments formed by recom bination were differentiated by their size, and their amount was measured directly. The amplified BCR fragment was $808 \mathrm{bp}$, the homologous internal standard was $602 \mathrm{bp}$, and the recombinant molecules formed were 698 and $712 \mathrm{bp}$ long. Serial dilutions of the homologous BCR internal standard $(2.5 \times$ $10^{3}, 5 \times 10^{3}, 7.5 \times 10^{3}, 1 \times 10^{4}, 2.5 \times$ $10^{4}$, and $5 \times 10^{4}$ molecules) were coamplified with $1 \times 10^{4}$ molecules of BCR cDNA using an extension time of $90 \mathrm{~s}$ and 30 amplification cycles. Two parallel reactions with $1 \mathrm{M}$ betaine and $10 \%$ DMSO added to the PCR were also carried out, and all reactions included negative controls. The reactions were repeated five times on separate days, and samples were analyzed by capillary electrophoresis.

The effect of the formation of recombinant molecules on the results of quantitative PCR with and without additives was tested by comparing the "observed" and the "corrected" results of amplification with the "expected" BCR cDNA value. The expected num ber of BCR molecules determined by absorbance measurement was $1 \times 10^{4}$. The observed values were determined from the peak area of BCR and internal standard measured after capillary electrophoresis. The $\log$ of the ratio of BCR:internal standard after PCR was plotted against the log of the amount of internal standard before PCR, and the initial amount of BCR cDNA was determined from the regression plot (Figure 1). The corrected values for BCR and internal standard were derived from adding the total area of the recom binant molecules to the observed peak area of the BCR cDNA and internal standard. This was based on the assumption that each recombinant molecule was produced from one BCR cDNA and one homologous internal standard molecule and that the sum of the total area of the recombinant mole- cules formed corresponded to the amount of product diverted from each template by recombination. A new plot using the corrected values was made, and the results of BCR quantitation were compared. All the regression plots were constructed using the Stat View 4.5 program $^{\circledR}$ (Abacus Concepts, Berkeley, CA, USA).

The observed and corrected results of BCR cDNA determinations by quantitative PCR with and without additives on the five different days are shown in Table 1. The table shows that mathematical correction of the results of am plification of BCR cDNA and the internal standard overestimates the observed $\mathrm{BCR}$ values. The explanation may be that the correction values were overestimated because direct amplification of the recombinant molecules generated during PCR also contributed to the final amount of recombinants measured. This proportion generated by direct amplification could not be determined separately from the amount of recombinant molecules formed by de novo synthesis and therefore was not accounted for in the correction. Thus, correction of observed results under our experimental conditions should be avoided because it caused disproportionate changes in the ratios of amplification products with subsequent alterations in the slopes of regression plots and overestimation of the observed BCR values (Figure 1).

The difference between the observed and expected BCR values was smallest when betaine was used in the PCR, while the addition of DMSO consistently overestimated the amount of initial BCR molecules, even though both agents suppressed in vitro recom bination (Table 1 and Figure 1). The results also show that assay reproducibility was improved by betaine. It may be that betaine stabilizes the polymeraseDNA complex in the PCR and hence reduces template switching and improves the processivity of the enzyme. This in turn not only leads to suppression of recombination but also maintains a more proportional amplification efficiency of the two fragments $(6,15)$. Betaine may prevent secondary structures forming in the template by destabilizing GC pair bonds and preventing those localized sequences from acting as pause sites that lead to temporary de- 
Table 1. Summary of the Results of Determining the Number of BCR Molecules by Competitive PCR

\begin{tabular}{|c|c|c|c|c|c|c|c|c|}
\hline $\begin{array}{l}\text { Number of BCR Molecules } \\
\text { Determined by Competitive PCR }\end{array}$ & PCR 1 & PCR 2 & PCR 3 & PCR 4 & PCR 5 & Mean & SD & $\operatorname{cv}(\%)$ \\
\hline Observed results without additives & 8990 & 12659 & 11003 & 9114 & 11944 & 10742 & 1651 & 15.4 \\
\hline Corrected results without additives & 9886 & 13155 & 12063 & 9099 & 12969 & 11434 & 1841 & 16.1 \\
\hline Observed results with $1 \mathrm{M}$ betaine & 9910 & 10833 & 10336 & 9561 & 10749 & 10278 & 544 & 5.3 \\
\hline Corrected results with $1 \mathrm{M}$ betaine & 9910 & 11014 & 10336 & 9561 & 11198 & 10403 & 700 & 6.7 \\
\hline Observed results with $10 \%$ DMSO & 13363 & 13813 & 13271 & 13117 & 10975 & 12908 & 1111 & 8.6 \\
\hline Corrected results with $10 \%$ DMSO & 13865 & 14388 & 13702 & 13117 & 10975 & 13209 & 1328 & 10.1 \\
\hline
\end{tabular}

\section{A}

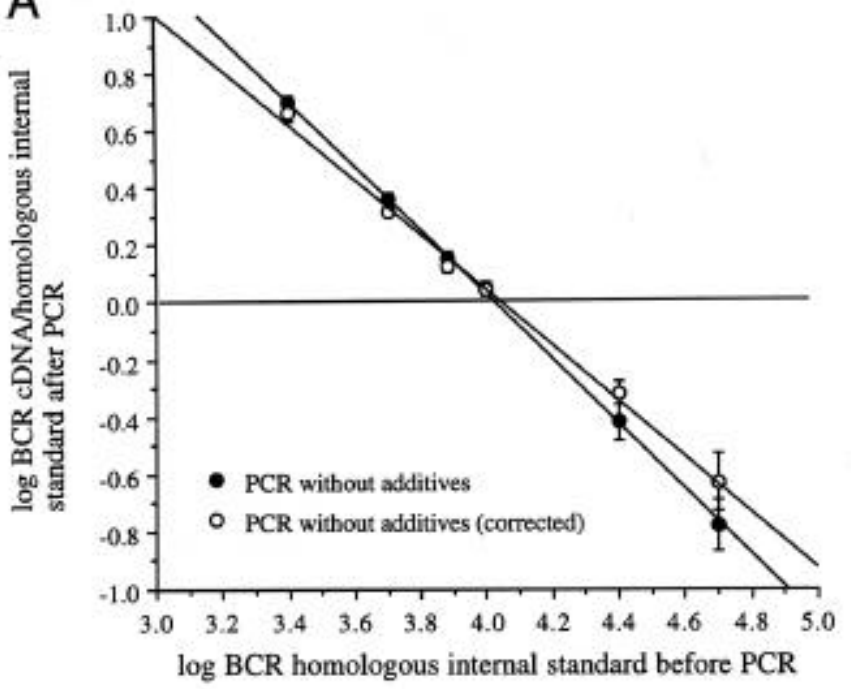

B

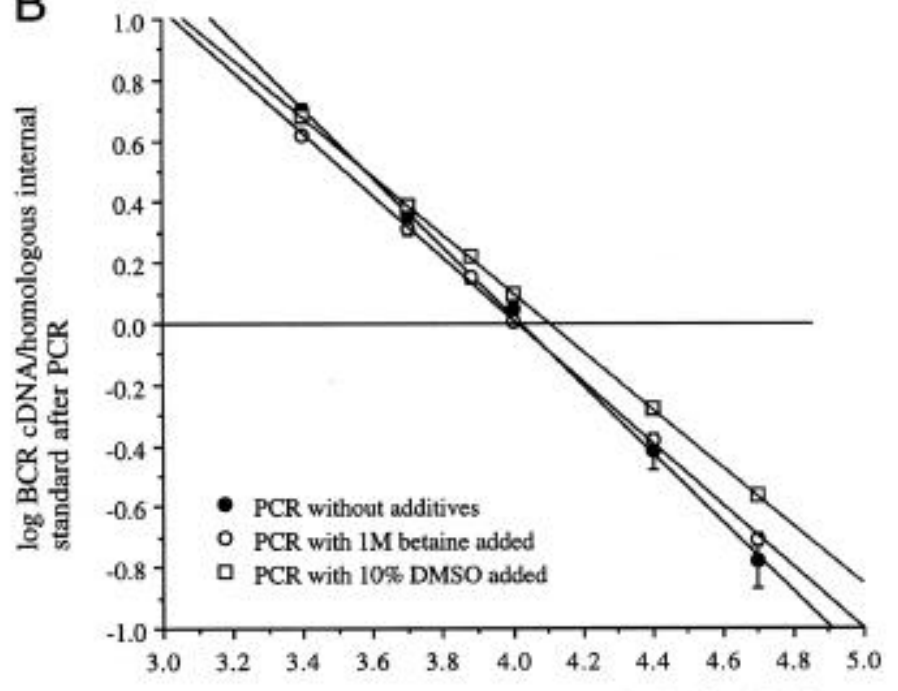

$\log$ BCR homologous internal standard before PCR crease in polymerase processivity and therefore reduce any differences in am plification efficiency between the two templates $(4,6,15)$. DMSO, another organic solvent that lowers the DNA melting temperature $(7,12)$, was also effective in reducing in vitro recombination, but in our study seemed to interfere with the amplification kinetics of the two templates during quantitative PCR (not shown). The other potential problem with DMSO was that we have previously found that $1 \mathrm{M}$ betaine did not influence the efficiency of PCR, while DMSO reduced the final amplification products by $20 \%$. Therefore, additives that impair PCR amplification efficiency may lead to false-negative results when attempting to quantitate rare cDNA molecules or when the amplification of one of the templates is less favored in a multiplex PCR.

Figure 1. Quantitation of BCR cDNA by com petitive PCR based on co-amplification of 2.5 $\times 10^{3}, 5 \times 10^{3}, 7.5 \times 10^{3}, 1 \times 10^{4}, 2.5 \times 10^{4}$, and $5 \times 10^{4}$ molecules of the homologous internal standard with $1 \times 10^{4}$ BCR cDNA molecules. The PCR was done on five different days, and the results expressed as mean \pm SE. Plot A shows the effect of correction for recombination on the results of competitive PCR. Regression analysis: $\mathrm{y}=4.554-1.132 * \mathrm{x}, \mathrm{R}^{\wedge} 2=0.999$ (PCR without additives) and $\mathrm{y}=3.904-0.965^{*} \mathrm{x}, \mathrm{R}^{\wedge} 2=0.996$ (PCR without additives/corrected). Plot B shows the effect of adding $1 \mathrm{M}$ betaine or $10 \%$ DMSO to the PCR on the observed values. Regression analysis: $\mathrm{y}=4.554-1.132 * \mathrm{x}, \mathrm{R}^{\wedge} 2=0.999(\mathrm{PCR}$ without additives), $\mathrm{y}=4.080-1.016 * \mathrm{x}, \mathrm{R}^{\wedge} 2=$ 0.999 (PCR with $1 \mathrm{M}$ betaine added) and $\mathrm{y}=$ $3.922-0.954 * \mathrm{x}, \mathrm{R}^{\wedge} 2=1.000$ (PCR with $10 \%$ DMSO added). 
Different additives may suppress in vitro recombination, but they are not equally optimal for improving the reproducibility of quantitative PCR. We found that $1 \mathrm{M}$ betaine was optimal for this purpose and recommend that different additives be tested in quantitative PCR assays to determine the most optimal agent and its concentration for improving reproducibility.

\section{REFERENCES}

1.Boer, P.H. and J. Ramamoorthy. 1997. How to correct for errors in mRNA quantitation by competitive PCR due to heteroduplex formation of amplification products. Cell Mol. Biol. 43:841-850.

2.Guieysse, A-L., D. Praseuth, M. Grigoriev, A. Harel-Bellan, and C. Hélène. 1995. Oligonucleotide-directed switching of DNA polymerase to a dead-end track. Biochemistry 34:9193-9199.

3.Hengen, P.N. 1997. Optimizing multiplex and LA-PCR with betaine. Trends Biochem. Sci. $22: 225-226$

4.Henke, W., K. Herdel, K. Jung, D. Schnorr, and S.A. Loening. 1997. Betaine improves the PCR amplification of GC-rich DNA sequences. Nucleic Acids Res. 25:3957-3958.

5.Judo, M.S.B., A.B. Wedel, and C. Wilson. 1998. Stimulation and suppression of PCR mediated recombination. Nucleic Acids Res. 26:1819-1825.

6.McDowell, D.G., N.A. Burns, and H.C. Parkes. 1998. Localised sequence regions possessing high melting temperatures prevent the amplification of a DNA mimic in competitive PCR. Nucleic Acids Res. 26:3340-3347.

7.Musielski, H., W. Mann, R. Laue, and S. Michel. 1981. Influence of dimethylsulfoxide on transcription by bacteriophage T3-induced RNA polymerase. Z. Allg. Mikrobiol. 21:447456.

8.Negroni, M., M. Ricchetti, P. Nouvel, and H. Buc. 1995. Homologous recombination promoted by reverse transcriptase during copying of two distinct RNA templates. Proc. Natl. Acad. Sci. USA 92:6971-6975.

9.Odelberg, S.J., R.B. Weiss, A. Hata, and R. White. 1995. Template-switching during DNA synthesis by Thermus aquaticus DNA polymerase I. Nucleic Acids Res. 23:20492057.

10.Pääbo, S., D.M. Irwin, and A.C. Wilson. 1990. DNA damage promotes jumping between templates during enzymatic amplification. J. Biol. Chem. 265:4718-4721.

11.Patel, R., C. Lin, M. Laney, N. Kurn, S. Rose, and E.F. Ullman. 1996. Formation of chimeric DNA primer extension products by template switching onto annealed downstream oligonucleotide. Proc. Natl. Acad. Sci. USA 93:2969-2974.

12.Pomp, D. and J.F. Medrano. 1991. Organic solvents as facilitators of polymerase chain reaction. BioTechniques 10:58-59.

13.Shammas, F.V., R. Heikkilä, and A. Osland. 2001. Fluorescence-based method for measur- ing and determining the mechanisms of recombination in quantitative PCR. Clin. Chim. Acta 304:19-28.

14.Shammas, F.V., J.A.M. van Eekelen, L. Wee, R. Heikkilä, and A. Osland. 1999. Sensitive and quantitative one-step polymerase chain reaction using capillary electrophoresis and fluorescence detection for measuring cytokeratin 19 expression. Scand. J. Clin. Lab. Invest. 59:635-642.

15.Weissensteiner, T. and J.S. Lanchbury. 1996. Strategy for controlling preferential am plification and avoiding false negatives in PCR typing. BioTechniques 21:1102-1108.

16.Zaphiropoulos, P.G. 1998. Non-homologous recombination mediated by Thermus aquaticus DNA polymerase I. Evidence supporting a copy choice mechanism. Nucleic Acids Res. 26:2843-2848

This work was supported by the Norwegian Ministry of Health and Social Affairs and the Norwegian Cancer Society. Address correspondence to Dr. Fuad V. Shammas, Department of Clinical Chemistry, Roagland Central Hospital, 4011 Stavanger, Norway.e-mail: shammas@online.no

Received 11 September 2000; accepted 26 January 2001.

Fuad V. Shammas, Reino Heikkilä, and Arve Osland Rogaland Central Hospital Stavanger, Norway

\section{RNA Extraction from Ethanol-Fixed Leuko- cytes Trapped on Polyeth- ylene Terephthalate Filter for RT-PCR Analysis}

BioTechniques 30:954-960 (May 2001)

Genetic diagnosis generally requires procedures performed in experimental laboratories. For example, chronic myeloid leukemia (CML) has been shown to be associated with a cytogenetic abnormality now known as the Philadelphia chromosome $\left(\mathrm{Ph}^{1}\right)$ and leukemiaspecific, chimeric bcr-abl messenger RNAs (bcr-abl mRNAs) (1,10). RTPCR analysis and fluorescence in situ hybridization (FISH) methods have been reported to be highly sensitive and reliable for diagnosis of CML and for monitoring of CML patients after bone marrow transplantation $(2,5)$. In these patients, the presence of mRNAs of bcrabl transcripts should be tested for routinely, although RNA preparation is difficult because RNA breaks easily during specimen storage and sampling. We previously reported a convenient and rapid method using synthetic polyethylene terephthalate (PET) from EDTA-anticoagulated blood samples and DNA extraction from such leukocytes (11). We therefore attempted to extract RNA from leukocytes adsorbed on PET filter and fixed with ethanol. We examined whether this method can be used for RT-PCR analysis.

Venous blood samples (each about 1 $\mathrm{mL}$ ) were obtained from three healthy adult donors (aged 30-36 years) (nos. 5-7) and seven interferon- $\alpha$ (IFN- $\alpha$ )treated patients (nos. 1-4 and 8-10) after obtaining informed consent. The samples were anticoagulated with $\mathrm{K} 2$ EDTA $(1.5 \mathrm{mg} / \mathrm{mL}$ blood). The blood was filtered through a syringe packed with PET (approximately $350 \mathrm{mg}$; Toyobo Gene Analysis, Osaka, Japan). About $10 \mathrm{~mL}$ physiological saline solution were passed through the syringe with the filtering material to remove erythrocytes and plasma. The filters were fixed with $5 \mathrm{~mL}$ ethanol for 30 min to $1 \mathrm{~h}$. Then, the filter, moistened with ethanol, was stored for one day and for another two weeks at $4^{\circ} \mathrm{C}$ before RNA extraction was performed.

To remove ethanol, filters (about 60 $\mathrm{mg}$ ) were washed three times with sterile physiologic saline just before extraction. The filter was treated with a Total RNA SafeKit ${ }^{\mathrm{TM}}$ (BIO 101, Carlsbad, CA, USA) according to the manufacturer's protocol. The extracted RNA solution $(200 \mu \mathrm{L})$ was then stored at $-20^{\circ} \mathrm{C}$. Extracted RNA was quantified by absorbance at $260 \mathrm{~nm}\left(\mathrm{~A}_{260}\right)$ using a spectrophotometer (U-2001; Hitachi, Tokyo, Japan). To examine the purity of extracted RNA, absorbance at $280 \mathrm{~nm}$ $\left(\mathrm{A}_{280}\right)$ also was measured, and the $\mathrm{A}_{260}$ : $\mathrm{A}_{280}$ ratio was calculated.

The amounts of RNA extracted from leukocytes stored for one day or another two weeks were $2.43 \pm 1.92(0.60-6.95)$ and $2.68 \pm 2.07(0.50-5.96) \mu \mathrm{g}$, respec- 